\title{
UNIDADE DO ORDENAMENTO JURÍDICO ${ }^{1}$
}

\author{
Friedrich Müller*
}

1 Sobre o conceito. 2 Origem histórica. 2.1 Direito racional. 2.2 Positivismo. 2.3 Crítica histórica. 3 Nexo com a proibição da negação do direito. 4 Crítica da unidade do ordenamento jurídico como crítica do positivismo. 5 Unidade da constituição. 5.1 Sobre o conceito. 5.2 Origem histórica. 5.3 Práxis dos tribunais. 5.4 Crítica pela teoria estruturante do direito. 6 Conclusões. Referências.

\section{RESUMO}

Uma expressão que encerra múltiplas atividades, a Unidade do ordenamento jurídico é tomada como uma característica ou axioma ou postulado do Direito. Filha do Direito Natural de tradução racionalista, foi adotada pelo Direito Positivo. No que toca a unidade como um todo e enquanto unidade da Constituição, a análise apresentada é conduzida sob os aspectos racionais, históricos e positivistas, assim como sob a orientação da teoria estruturante do Direito. A conclusão é que a Unidade do ordenamento jurídico - como um dado ou uma meta inspiradora da prática jurídica - é ilusória.

Palavras-chave: Unidade. Ordenamento jurídico. Constituição. Teoria estruturante do Direito. Ilusão.

\section{SOBRE O CONCEITO}

Compreende-se por "unidade" do ordenamento jurídico, e.g. uma qualidade do sistema científico referido ao Direito Positivo, mas também uma qualidade da abordagem analítica e da sua referência, i. e., uma unidade do conhecimento científico. A "unidade" do Direito pode ser introduzida como axioma bem como postulado do trabalho jurídico. Entretanto, ela se transmuda não apenas de acordo com a localização, mas também de uma disciplina para outra, assim entre o Direito Público e o Direito das Gentes, o Direito Internacional

1 Tradução de Peter Naumann. Revisão de Paulo Bonavides. Publicado em: MÜLLER, Friedrich. O novo paradigma do direito. 3.ed. São Paulo: Revista dos Tribunais, 2013. pp. 101 ss.

* Friedrich Müller nasceu em 1938. Estudou Direito e Filosofia em Erlangen-Nurembergue e Friburgo-em-Brisgau (Alemanha). Em 1964, doutorou-se em Direito pela universidade de Friburgo-em-Brisgau e, em 1968, obteve o título de livre-docente e a licença para assumir cátedras nas áreas de Direito do Estado, Direito Administrativo, Direito Eclesiástico, Filosofia do Direito e do Estado, bem como Teoria do Direito. De 1968 a 1971, lecionou na Universidade de Friburgo-em-Brisgau. Em 1971, assumiu uma cátedra na Faculdade de Direito da Universidade de Heidelbergue, onde coordenou o Núcleo de Direito Público de 1973 a 1975. A partir de 1975, e novamente a partir de 1979, foi diretor daquela Faculdade de Direito. Desde 1989, vem-se destacando nas áreas de pesquisa e de publicações científicas. Também tem atuado como professor-visitante e pesquisador em diversas universidades estrangeiras, sobretudo na África do Sul e no Brasil. Além de sua carreira jurídica Friedrich Müller também se destaca como literato (poesia e prosa), tradutor e cinesta. E-mail: <mullerfedja@arcor.de>. 
Privado, o Direito Penal e o Direito Civil. Na sua mistura com outras variantes de significado o argumento revela ser usado de modo muito inseguro.

\section{ORIGEM HISTÓRICA}

\subsection{DIREITO RACIONAL}

A expressão multívoca da unidade do ordenamento jurídico é filha do Direito Racional da tradição racionalista, tendo sido adotada mais tarde pelo positivismo. O jusnaturalismo de data mais recente bem como o positivismo procedem axiomaticamente, querem construir um sistema rigoroso do conhecimento exato e carecem do raciocínio codificante: o legislador regulamentou em abordagem autoritária tudo o que merece ser regulamentado; fora das suas instruções só se pode conceber o "espaço vazio de direito" ["rechtsleerer Raum"]. Considera-se "coerente" ["geschlossen"] o Direito sistematizado e formalizado, monopolizado e, burocratizado pelo Estado institucionalizado continental da Europa moderna. Todo o comportamento humano deverá ser normatizável, antecipável por meio de normas. Ao ordenamento jurídico enquanto engrenagem jurídica [Rechtsbetrieb] corresponde à imagem da "unidade" do estoque de normas. A doerência enquanto integralidade bem como enquanto isenção de contradições internas foi o pressuposto ingênuo da ideia da legislação abrangente, do otimismo social da época do Direito Racional, sem com isso chegar a ser um programa da ciência e prática jurídicas.

\subsection{POSITIVISMO}

Somente a ciência das pandectas e o positivismo legalista exageraram esse enfoque na direção da pretensão de poder operar a ciência jurídica como sistema conceitual coerente, de poder derivar decisões por via da lógica a partir do sistema, do conceito e da doutrina [Lehrsatz] e de poder solucionar casos jurídicos por meio da subsunção silogística. Os conceitos jurídicos parecem oferecer um numerus clausus de axiomas. Não mais o próprio ordenamento jurídico, mas o sistema conceitual de uma ciência jurídica purista deve estar definido necessariamente por "unidade". A realidade é reprimida da área de atuação do trabalho jurídico. O positivismo pergunta como a ciência jurídica se poderia tornar autônoma, como ela poderia proceder "de modo puramente jurídico". O fato de essa orientação prévia constituir um fator político já foi percebido pelo positivismo dos Gründerjahre* (v. Gerber). ${ }^{1}$ A aparente coerência e não contraditoriedade do direito dogmaticamente formalizado, a sua "força de expansão lógica" (Bergbohm)², a capacidade dos conceitos jurídicos de "copular" e "gerar novos [conceitos]" (assim o novem Ihering) não traem apenas a fé na inimpugnabilidade da lógica jurídica, mas também uma política científica bem definida. 


\subsection{CRÍTICA HISTÓRICA}

Por volta da última virada do século essa doutrina dominante foi contestada. Falava-se, então, do "dogma errôneo da coerência do sistema jurídico" (Georg Jellinek ${ }^{3}$, similarmente Erich Jung). ${ }^{4}$ A doutrina da Escola do Direito Livre, a jurisprudência de interesses e o debate em torno das orientações do Direito Público na década de 1920 tornou patente o fracasso da tese cripto-jusnaturalista da unidade. Em frente ampla, os autores da bibliografia jurídica especializada bandearam-se para o campo das metáforas de "sistemas" jurídicos, abertos, fragmentários, não axiomáticos, não dedutíveis, de sistemas ditos móveis. Os problemas reconhecíveis na práxis cotidiana do trabalho jurídico passaram a assumir a liderança, relegando a um segundo plano a fé no sistema e na unidade.

\section{NEXO COM A PROIBIÇÃO DA NEGAÇÃO DO DIREITO}

Para o positivismo o Direito deve, para poder ser "aplicável" logicamente, ser pressuposto não apenas como isento de contradições, mas também como isento de lacunas. Tal estado tinha sido a meta das codificações do Direito Racional, há muito abandonada. A ciência das pandectas e o positivismo fizeram com que o postulado se deslocasse para a ausência de lacunas, não do sistema de normas, mas do sistema de conceitos. Essa metafísica duvidosa de um jusnaturalismo burguês dos Gründerjahre desempenhava também uma função política de primeira ordem. O debate em torno do assim chamado direito jurisprudencial procurou aqui a sua localização, desde a Escola do Direito Livre. Deve-se registrar aqui que a proibição da negação do Direito das sociedades modernas não necessita da ausência de lacunas enquanto correlato, conforme foi afirmado, pois deve-se distinguir, por um lado, entre o estoque de normas e as necessidades efetivas da práxis e, por outro lado, entre o Direito material e o Direito processual. Medida pela demanda social de normatização, cada ordenamento jurídico evidenciou ser incompleto até a atualidade. No Estado de Direito, uma parte litigante recebe mesmo em uma decisão de indeferimento no conteúdo, que, no entanto, é processualmente correta, a resposta do direito vigente, que lhe cabe de direito. A proibição da negação do Direito não força a suposição de uma unidade coerente.

\section{CRÍTICA DA UNIDADE DO ORDENAMENTO JURÍDICO COMO CRÍ- TICA DO POSITIVISMO}

Desde a Escola do Direito Livre, a jurisprudência de interesses e a ciência jurídica de orientação sociológica a objeção tradicional contra os dogmas unitaristas afirma que a integralidade do ordenamento jurídico seria apenas um postulado, pois o juiz sempre se veria diante da necessidade de "preencher lacunas da lei por meio de um ato de criação do direito" (Arthur Kaufmann). ${ }^{5}$ Tal crítica não é suficientemente ampla. Ela aponta para a experiência cotidiana da insuficiência lógica da práxis jurídica, para o fracasso dos ideais do "silogismo" e 
da "subsunção". Ocorre que aqui o conceito da norma e as qualidades do que ele designa não são pensadas até as suas últimas consequências. Com sua imagem do direito como unidade, com sua compreensão da decisão como subsunção lógica, com sua eliminação de todos os elementos da ordem social que não foram não dogmatizados no texto da norma, o positivismo com efeito seguiu e continua seguindo uma ficção. Mas as doutrinas do Direito Livre, do Direito determinado por interesses, do Direito jurisprudencial, a Tópica, a Hermenêutica originária das Ciências Humanas [geisteswissenschaftliche Hermeneutik], o Decisionismo, a Doutrina Integracionista e os antipositivismos restantes preferiram formular críticas no nível dos detalhes em vez de questionar a norma e o conceito de norma.

Se, no entanto, tanto a norma jurídica e o texto da norma quanto à norma jurídica e a norma de decisão forem distinguidas sistematicamente (por parte da Teoria Estruturante do Direito), a ideia do "Direito Vigente" se esclarece: o que se costuma designar por esse termo é o conjunto dos textos das normas, que devem ser desenvolvidos apenas no caso na direção de normas jurídicas, de acordo com regras de método, sendo que essas normas jurídicas, por sua vez, devem ser desenvolvidas na direção de normas de decisão. Esclarece-se, outrossim, que "unidade", "integralidade" e "coerência" foram confundidas com a positividade e equivalência das normas de uma codificação bem como com a identidade do estoque de normas consigo mesma.

\section{UNIDADE DA CONSTITUIÇÃO}

\subsection{SOBRE O CONCEITO}

Esse enfoque também permite descrever mais precisamente os modos de utilização da expressão "unidade da constituição". A teoria estruturante da constituição definiu com base nesse exemplo o perfil de alguns tipos de concepções de unidade formal (ausência de lacunas - não contraditoriedade; unidade do texto, unidade do nível hierárquico de fontes do direito - unidade da estrutura da constituição) e de várias teorias da unidade em termos de conteúdo, a saber modalidades ideológicas, de história da constituição, legitimadoras, funcionais e metodológicas do recurso a uma unidade da constituição.

\subsection{ORIGEM HISTÓRICA}

As origens da expressão "unidade da constituição" estão na República de Weimar. Para Smend", uma constituição é a normatização de aspectos individuais do processo no qual o Estado produz constantemente o seu processo vital; por isso esta não deve visar a particularidades, mas "a totalidade do Estado e a totalidade do seu processo de integração". Estamos aqui não apenas diante de um pensamento que visa à totalidade, mas diante de um pensa- 
mento a partir da totalidade e da sua unidade. Kelsen ${ }^{7}$ registrou o aspecto problemático desse holismo. Para ele, a unidade do Estado somente pode ser fundamentada normativamente, o ordenamento jurídico constitui uma unidade apenas enquanto ordenamento lógico: com a qualidade de poder ser descrito em normas jurídicas [Rechtssätzen] que não se contradigam reciprocamente. A grandeza formal "norma fundamental" constitui a unidade na multiplicidade das normas. Diante disso, Carl Schmitt ${ }^{8}$ chamou a atenção às insuficiências de uma acepção que se restringe ao imperativo isolado pelo positivismo e, conforme devemos acrescentar, sobretudo à figura lingüística da norma, ao texto da norma. Mas a vontade existente por força do decisionismo, que só quer a si mesma, atropela toda e qualquer normatividade materialmente vinculada: "a totalidade da unidade política" (Schmitt) 9 oferece um exemplo extremado de holismo não estruturado. Totalidade enquanto fonte de argumentos tende ao poder e à sua manipulação incontrolada. A essa tendência o Estado de Direito contrapõe os imperativos da vinculação ao direito e à constituição, da determinidade do suporte fático, da clareza dos métodos e da fundamentação racional suficiente. Inferências a partir do todo e da sua unidade não atendem suficientemente às exigências de métodos democraticamente vinculados e configurados conforme o Estado de Direito.

\subsection{PRÁXIS DOS TRIBUNAIS}

Na práxis, a Corte Constitucional Federal procura impor desde a sentença sobre o Estado do Sudoeste (BVerfGE 1,14 ss.) a visão da Lei Fundamental como uma unidade. O Superior Tribunal Federal segue essa linha ocasionalmente com fórmulas do tipo "unidade indivisível" ou "totalidade da ordem de valores". O Poder Judiciário gerou um caos de modos de utilização desse argumento. Assim, a $2^{\text {a }}$ Câmara da Corte Constitucional Federal afirma na sua tese sobre a unidade que haveria diferenças hierárquicas genéricas no direito constitucional positivo; contrariamente, na acepção da $1^{a}$ Câmara da mesma Corte infere-se, desde a sentença sobre a igualdade de direitos (BVerfGE 3,225 ss.), justamente da unidade da constituição que as normas da Lei Fundamental devem em princípio ter a mesma dignidade hierárquica. Do ponto de vista do Estado de Direito, a interpretação da $2^{\mathrm{a}}$ Câmara, em conformidade com o princípio, revela-se insustentável.

\subsection{CRÍTICA PELA TEORIA ESTRUTURANTE DO DIREITO}

Um exame sob perspectivas formais, de conteúdo e de metodologia, conduz a resultados claros: a Lei Fundamental nem é necessariamente destituída de lacunas nem ea ipsa isenta de contradições. Mas ela ordena a integralidade do texto e o rigor do texto, nesse sentido, uma unidade do documento constitucional em nível formal. Ele não apresenta graus hierárquicos distintos nem dissocia grupos individuais de normas juriciamente dos outros grupos. Por isso a Lei Fundamental conhece uma unidade do grau hierárquico das fontes do 
direito e, desconsideradas as prescrições sobre o estado de emergência, uma unidade da sua estrutura normativa. Para esses casos, a expressão "unidade da constituição" poderia ser utilizada, embora seja supérflua. O que ela diz resulta das qualidades genéricas da constituição escrita ou das normas constitucionais individuais. Todas as perguntas por uma unidade da constituição são, de qualquer modo para a Lei Fundamental da República Federal da Alemanha, respondidas pelas qualidades da sua positividade. A positividade da constituição resolve tanto os casos nos quais o discurso da unidade da constituição fracassa diante da própria constituição (ausência de lacunas, isenção de contradições, unidade ideológica), como também os casos nos quais a tese da unidade já se vê fundamentada pelo Direito Positivo (unidade legimadora, unidade funcional, unidade enquanto meio da interpretação sistemática e harmonizadora da constituição). $\mathrm{O}$ mesmo vale para os tipos já mencionados supra (unidade do documento, unidade do grau hierárquico das fontes do direito bem como da estrutura normativa da constituição).

\section{CONCLUSÕES}

A expressão "unidade da constituição" pode ser abandonada também quando ela poderia ser utilizada com sentido. Ela não pode continuar servindo a tentativas de apagar a linha de fronteira entre argumentos orientados segundo as normas e os argumentos de política jurídica desvinculada do Direito. A tentativa de salvação estimada desde os escritos de Smend ${ }^{10}$ de considerar a unidade não como um dado [gegeben], mas sim como uma tarefa [aufgegeben] também não leva mais longe, conforme a práxis do tribunal supremo mostra involuntariamente. Se a unidade não existe enquanto dado nem pode ser tornada plausível, ela também não existe como meta a ser atingida na práxis. Do contrário, só substituiremos uma ilusão por outra, a ilusão positivista pela ilusão antipositivista. $O$ que conduz mais longe é uma estruturação pós-positivista do campo de problemas.

Os argumentos enganosos [schillernd] da "unidade", seja do ordenamento jurídico na sua totalidade, seja da constituição, levaram a caminhos errados. Constituem exemplos de um holismo irracional do trabalho jurídico que pode ser abandonado sem prejuízo desse mesmo trabalho, que deveria ser abandonado no interesse de uma atuação dos juristas em conformidade com o Estado de Direito.

\section{REFERÊNCIAS}

BERGBOHM, Karl. Jurisprudenz und Rechtsphilosophie. Leipzig: Verlag Von Duncker \& Humblot, 1892.v. 1.

BURCKHARDT, Walter. Die Lücken des Gesetzes und der Gesetzesauslegung. Bern: [s.n], 1925. 
ENGISCH, Karl. Der rechtsfreie Raum. Zeitschrift für die gesamte Strafrechtswissenschaft. Journal of Institutional and Theoretical Economics / Journal of Institutional and Theoretical Economics, Germany, Bd. 108, H. 3, p. 385-340, 1952.

. Die Einheit der Rechtsordnung. Heidelberg: [s.n.], 1935.

GERBER, Carl-Friedrich-Wilhelm von. Grundzüge des deutschen Staatsrechts. 3. ed. Leipzig: [s.n.], 1880.

JELLINEK, Georg. Allgemeine Staatslehre. 3. ed. Darmstadt: [s.n.], 1960.

JUNG, Erich. Von der 'logischen Juristenfakultät für Heinrich Dernburg, Geschlossenheit. In: FESTGABE des Rechts, Giessener Juristenfakultät für Heinrich Dernburg. Berlin: W. H. Muller, 1900.

KAUFMANN, Arthur. Gedanken zu einer ontologischen Grundlegung der juristischen Hermeneutik. In: HORN, Norbert Horn. Europäisches Rechtsdenken in Geschichte und Gegenwart: festschrift für Helmut Coing zum 70. München: Geburststag, 1982. v. 1, p. 5317. KELSEN, Hans. Reine Rechtslehre. 2 ed. Viena: Deuticke, 1960.

LABAND, Paul. Das Staatsrecht des Deutschen Reiches. 5. ed. Tübingen:[s.n.], 1911.v. 1. LARENZ, Karl. Methodenlehre der Rechtswissenschaft. 5. ed. Heidelberg: [s.n.], 1983. LUHMANN, Niklas. Die Einheit des Rechtssystems. Rechtstheorie 14, H. 2, p. 129-154, 1983. MÜLLER, Friedrich. Die Einheit der Verfassung: elemente einer Verfassungstheorie III. Berlin: [s.n.], 1979.

Strukturierende Rechtslehre. 2. ed. Berlin: [s.n.], 1994.

Juristische methodik. 7. ed. Berlin: [s.n.], 1997.

SCHMITT, Carl. Vergfassungslehre. 4. ed. Berlin: [s.n.], 1965.

SMEND, Rufolf. Verfassung und Verfassungsrecht. München: [s.n.] 1928.

1 GERBER, Carl-Friedrich-Wilhelm von. Grundzüge des deutschen Staatsrechts. 3. ed. Leipzig: [s.n.], 1880.

2 BERGBOHM, Karl. Jurisprudenz und Rechtsphilosophie. Leipzig: Verlag Von Duncker \& Humblot, 1892. v. 1.

3 JELLINEK, Georg. Allgemeine Staatslehre. 3. ed. Darmstadt: [s.n.], 1960.

4 JUNG, Erich. Von der 'logischen Juristenfakultät für Heinrich Dernburg, Geschlossenheit. In: FESTGABE des Rechts, Giessener Juristenfakultät für Heinrich Dernburg. Berlin: W. H. Muller, 1900.

5 KAUFMANN, Arthur. Gedanken zu einer ontologischen Grundlegung der juristischen Hermeneutik. In: HORN, Norbert Horn. Europäisches Rechtsdenken in Geschichte und Gegenwart: festschrift für Helmut Coing zum 70. München: Geburststag, 1982. v. 1, p. 5317.

6 SMEND, Rufolf. Verfassung und Verfassungsrecht. München: [s.n.] 1928.

7 KELSEN, Hans. Reine Rechtslehre. 2 ed. Viena: Deuticke, 1960.

8 SCHMITT, Carl. Vergfassungslehre. 4. ed. Berlin: [s.n.], 1965.

9 SCHMITT, Carl. Vergfassungslehre. 4. ed. Berlin: [s.n.], 1965.

10 SMEND, Rufolf. Verfassung und Verfassungsrecht. München: [s.n.] 1928. 


\title{
THE UNITY OF LEGAL SYSTEM
}

\begin{abstract}
An expression that carries multiple meanings, the unity of the legal system is taken as a legal characteristic, axiom or postulate. Arising from Natural Law of the rationalist tradition, the idea of unity was adopted by Positive Law. Whether regarding the legal system as a whole or the Constitution, the analysis presented here is conducted under rational, historical and positivist aspects, and also under the guidance of the Structuring Theory of Law. The conclusion is that the unity of the legal system - as a data or as an inspiring goal of legal practice - is illusory.
\end{abstract}

Keywords: Unity. Legal system. Constitution. Structuring Theory of Law. Illusion.

Submetido: 17 abr. 2017

Artigo convidado 